\title{
Simulation in Higher Education: A sociomaterial view
}

\begin{abstract}
This article presents a sociomaterial account of simulation in higher education. Sociomaterial approaches change the ontological and epistemological basis for understanding learning, and offer valuable tools for addressing important questions about relationships between university education and professional practices. Simulation has grown in many disciplines as a means to bring the two closer together, yet the theoretical underpinnings of simulation pedagogy are limited. This paper extends the wider work of applying sociomaterial approaches to educational phenomena, taking up Schatzki's practice theory as a distinctive basis for doing so. The question 'What is being simulated?' is posed, prompting discussion of multiple bodies, performances and experiences. The potential of adopting such a framework for understanding simulation as a pedagogic practice that brings the classroom and workplace together is illustrated with reference to clinical education in nursing.
\end{abstract}

Keywords: simulation; sociomaterial perspectives; practice theory; higher education

\section{Introduction}

This paper brings sociomaterial theory to bear on questions of simulation in higher education. Simulation has proliferated in contexts where universities are charged with preparing graduates for work in specific professions, seen as a bridge between the classroom and the world of work (Gonzci, 2013). We begin by outlining what are referred to as 'sociomaterial' approaches, explaining their ontological and epistemological breaks from dominant modes of thinking in education. We then focus on simulation pedagogy, and identify a paucity of theoretical work as a feature of the current literature. After explaining several key concepts we offer an account of simulation drawing primarily on Schatzki's practice theory. In doing so we take clinical simulation as a focus, and make reference to our observations of simulation classes in an undergraduate nursing degree. In answer to the question 'What is being simulated?', we describe the emergence of multiple bodies (technical, clinical and human patient), discuss the embodied performances of simulation, and consider the diverse experiences of students, all from a sociomaterial perspective. We connect our clinical focus to the professions more generally, and finally return to where the paper begins, situating our argument within the changing philosophical foundations of educational and workplace learning theory.

New philosophical bases for understanding relationships between learning and work Educational research and theory are being radically reshaped by philosophical developments that emphasise materiality and embodiment. The term 'sociomaterial' is used in reference to diverse approaches that break out of structure/agency divides, eschew representationalist and disembodied views of knowledge, and decentre human subjects (Fenwick, Edwards \& Sawchuk, 2011). At hand here are a range of ontological shifts, which place emphasis on the relational basis of social phenomena (as opposed to singular entity views) and on enactment - relations in practices not in some kind of abstract sense. Mulcahy (2013) uses actor-network theory to rework the notion of 'transfer', based on a relational, non-representational epistemology that does not separate meaning from matter. Such approaches explore how both are produced through relationships established in practices: the focus is on performance, not on stable isolated forms. Practice theory is emerging as an important and distinct line of thinking within this broader tradition (Kemmis et al., 2014; 
Practice theory is not a unified, singular approach, but signals a body of work that takes up the idea of social practices as a fundamental unit of (co-)existence, and therefore an appropriate focus in analysis of any social phenomena (see Schatzki et al., 2001). Schatzki's practice theory (1996, 2002, 2010b, 2012) stands apart from others in many nuanced ways. Key to these are his defence of residual humanism and associated rejection of symmetry between the human and non-human (2002). Many of the concepts we outline below, particularly his site ontology, prefiguration, and practical intelligibility constitute what we regard as distinctive hallmarks of a Schatzkian approach. Notions of multiplicity and emergence are more widely shared across sociomaterial approaches, though of course they have their particular Schatzkian inflections and nuances. Schatzki's practice theory is an exercise in philosophy, grounded in Wittgenstein and later Heidegger. There is therefore translational work required to bring such a framework into connection with questions specifically pertaining to education, learning and the professions. The volume edited by Hager, Lee \& Reich (2012) marks a significant contribution in this regard, while also bringing practice theoretical approaches alongside those informed by complexity theory, actor-network theory, and other sociomaterial approaches. This line of thinking is taken up by Hopwood, Abrandt Dahlgren and Siwe (2014) in their account of simulations based on live 'professional patients' that links Schatzki's site ontology to the idea of a 'sociomaterial curriculum'.

Many university degrees aim to prepare students for future work practices in specific professions, and simulation is a key feature of university based professional formation. Sociomaterial theories conceive knowing and learning through metaphors of emergence instead of possession / acquisition or participation, using a philosophical understanding of practices as the basis for changed assumptions about the nature of learning (Hager, 2011; Hager et al., 2012). Learning is viewed as emerging in complex (non-linear) systems in which human actors and the material environment produce and shape each other. Ontologically, knowledge, meaning, bodies, and objects constantly emerge through associations or assemblages as practices unfold. This has a strong bearing on 'the mistaken nature of the formerly prevalent assumption that all of the learning needed for successful performance in an occupation can be specified in advance and imparted in a formal course' (Hager, 2011, p. 17).

\section{Simulation pedagogy and the need for new theoretical approaches}

In its most basic sense, simulation refers to any kind of model or device used to bring elements of one reality into another (eg. drawings of anatomy simulate a body), and indeed the use of simulators as an educational tool is far from new, dating back in medicine to at least the $17^{\text {th }}$ century (McGaghie, Issenberg, Petrusa \& Scalese, 2010). There has been a marked increase in the use of simulation in higher education curricula and financial investments made in simulation technologies. Many forces are driving this growth, raising important questions about how we understand simulation pedagogies. These include concerns about the readiness of graduates for work (Kelly, Forber, Conlon, Roche \& Stasa, 2014), as is evident in discourses around simulation in health ensuring 'safe' clinical practice (Dieckman \& Krage, 2013). In some fields, providing students access to work settings is becoming a challenge and so simulation is conceived in terms of its potential to stand in for placements (Rochester et al., 2012). Simulation is also seen as an opportunity to integrate different aspects of curricular content that are learned separately elsewhere, to provide an environment where mistakes can be made safely (without negative consequence for others), to standardise learning experiences (compared to the variance associated with work placements) and to address perceptions that university-based learning lacks authenticity or relevance in practice (Gonzci, 2013). Here we can see traces of a 'mirror logic', closely tied to ideas of fidelity: the idea is that something is produced in universities that (more or less) faithfully reflects what exists outside (ie. in the world of work). 
A sociomaterial approach provides a valuable basis to disrupt dominant approaches and offer new insights into simulation-based education in tertiary settings. Although our argument is not limited in its relevance to any one particular field, we focus on clinical simulations in nursing. This shapes our reference to existing literature, and enables us to provide empirical illustrations from observations of clinical simulation scenarios within an undergraduate nursing degree in an Australian university. All the scenarios involved use of a 'high-fidelity' manikin (SimMan ${ }^{\mathrm{TM}}$ ), which has a detectable pulse, breath, and blood pressure. SimMan responds to external actions (such as chest compressions) and can 'speak' via a microphone located nearby, for example in a control room. In our example, each simulation scenario involved five or six student roles, while remaining students (out of a total of 20-25) observed the action via live video relay. As is customary in this kind of simulation pedagogy, each scenario involved a general briefing about learning objectives and the 'patient', allocation of students to roles, technical briefing around the equipment, the simulation itself, and then a plenary debrief involving acting and observing students.

There are large bodies of literature on simulation in particular professional fields. In clinical disciplines, the dominant focus is on establishing whether, and to what extent, simulation is effective in ensuring safe practices in 'real' clinical settings (eg. Arthur, Levett-Jones \& Kable, 2013). Outlines of instructional design features seek to specify the conditions under which students can learn to perform particular features that will be required of them in their future work (eg. Issenberg, McGaghie, Petrusa, Lee Gordon \& Scalese, 2005).

The paucity of rich theoretical work in simulation pedagogy is an explicit cause of concern. Dieckmann (2009) seeks to undermine the misleading conclusion that simulation in itself leads to learning, asserting that despite evidence of the 'face value' of simulation, understanding of why and how simulations work remains poor. Explicit calls for new theoretical work include: a critique of operational concerns and neglect of theoretical groundwork (Berragan, 2011); the need for theorised process-oriented analyses of current simulation practice (Dieckmann et al., 2012); the lack of an ideological basis for simulation and need to move away from a fixation on technology (Schiavenato, 2009); and, the need to balance teaching-focused with learning-focused theoretical work (Kaakinen $\&$ Arwood, 2009). In this paper we take up Gonzci's (2013) vision of the potential of simulation as a means to bridge higher education and work, and Crookall's (2011) argument that our understanding of related pedagogic practices can be enhanced by further developing the philosophical tools for conceptualising simulation.

\section{Key Concepts}

In this section we outline several related concepts that provide the foundation for the discussion that follows. This does not adequately capture the richness of any one sociomaterial approach, let alone the distinctions between, say, actor-network theory, and practice theory. However these concepts do speak to the important ontological shifts at play in sociomaterial theorising, and prove particularly fertile in relation to questions of simulation pedagogy. Our primary reference is to practice theory, in particular the work of Schatzki (1996, 2002, 2010b), extending an ongoing conversation in which questions of learning are framed by Schatzki's ideas (Green, 2009; Hager et al., 2012; Hopwood, 2014a,b,c; Hopwood et al., 2014; Manidis \& Scheeres, 2013).

\section{Site ontology and practical intelligibility}

Schatzki (1996) developed his practice theory in response to problems associated with taking the individual as the ontological point of departure, instead pointing to practices. His 'site ontology' asserts a strong role for materiality. Materiality is not just a context for or used in social practices. Rather the material world is seen as a dimension of all social phenomena. The two are seen to constitute each other, and the site implies both dimensions. This can be illustrated through thinking about signatures and acts of signing. The act of signing produces the material artefact, and is itself accomplished through actions of a material body and accompanying pen, paper etc (see Hopwood, 
2014a). The signature and signing constitute each other. Practices are spatially and temporally dispersed, embodied and material arrays of human activity (doings and sayings) (Schatzki, 2002); they are never immaterial because all practices are performed bodily.

Investigating social phenomena through my ontology directs attention to how practices and arrangements causally relate, how arrangements prefigure practices, how practices and arrangements constitute one another, and how the world is made intelligible through practices. (Schatzki, 2010a, p. 146).

Practical intelligibility is important in the account of simulation that follows. Practices mediate the causal relevance of materiality, and material features alone do not determine the particular site established at any moment (Schatzki, 2002). A chair may be made intelligible so as to produce a site of sitting (if someone sits on it), but it may also be part of the production of a different site if someone stands on it to reach a high shelf, or hangs a coat on it to dry. Schatzki thus addresses the problem of the separation of meaning and matter, within a view that is intimately tied to performance. When considering simulation scenarios, our attention is directed to the different ways in which objects are made practically intelligible. This leads us to the question of emergence.

\section{Emergence, prefiguration and multiplicity}

Sociomaterial approaches to understanding learning may be distinguished from others through their metaphors of emergence (Hager, 2011). This reflects the performative or practice-based aspects of a site ontology, and links us to Schatzki's concept of prefiguration. Given a site is a product of mutually constituted practices and material arrangements, the sites of work or learning are always an in-the-moment accomplishment. The particular actions, material arrangements and forms of intelligibility that link them are, in Schatzki's (2010b) view, indeterminate (not yet fixed) until the moment of their occurrence.

This emergence is not random or devoid of shaping by phenomena that pre-exist them. For Schatzki, material arrangements can have causal power, while human actions can be oriented towards changing material states of affairs. His idea of prefiguration relates to what is often conceived in terms of enabling or constraining. Materiality prefigures practices insofar as it may make some courses of action more or less straightforward. By qualifying actions in these ways prefiguration organises the future but does not determine it (Schatzki, 2000, 2002, 2010b). Prefiguration has other origins too; in shared forms of understanding, intentions and attachments (teleoaffective structures) and rules (including social norms).

Multiple realities can co-exist in ontologies that emphasise emergence. Informed by actor-network theory, Mol (2002) shows how the practices of treating atherosclerosis enact the patient body in different ways, producing 'the body multiple'. Thrift (2007) argues that non-representationalism, to which sociomaterial approaches subscribe, does not require situations to be resolved into authentic, singular wholes: instead there is tolerance of simultaneous multiplicity. Schatzki (2010b, 2012) describes practices as spaces of multiplicity, with considerable scope for variation in the performances that uphold them, forms of practical intelligibility and material arrangements with which they are bundled.

The idea of multiplicity departs from existing accounts of clinical simulation pedagogy that, as we have noted above, tend towards reductive (and by implication singular) understandings. The idea of emergence further feeds this as it contests a linear, pre-specifiable view, while a site ontology foregrounds materiality enabling us to explore simulator technologies such as SimMan without the analysis being driven or determined by them.

\section{What is Being Simulated?}


We recognised the potential constraints inherent in following received wisdom, which implies the most important questions relate to how realistic simulation should be, and how it should be arranged to ensure particular pre-specified performance outcomes (eg. Issenberg et al., 2005). So we asked the deceptively simple question: 'What is being simulated?'. In developing our answer, we draw on the concepts outlined above to discuss how bodies, performances and experiences are all being simulated through emergent, multiple, bundles of practices with the materialities of the simulation classroom.

\section{Simulated Bodies}

In clinical settings, the answer to the question 'What is being simulated?' can be directed to the version of a patient's body. In other settings the same logic would focus on whatever the material artefact deployed for real-world 'replication' might be. Johnson $(2005,2008)$ shows how the same equipment may or may not function as intended in simulation depending on the way clinical practices are performed in particular contexts. A sociomaterial approach goes beyond equipment itself, looking at performances and materiality in relation to each other. In Schatzkian terms this is the bundling of practices and material arrangements. What is interesting pedagogically in simulation is not what SimMan or other technologies can do, or how realistic they are, but how they are made intelligible in practices that bring about learning. Our account is one of multiple bodies being simulated - through doings and sayings bound together with materiality. This builds on Nystrom, Dahlberg, Hult \& Abrandt Dahlgren (2014), who describe the enactments around SimMan, rather than its technological affordances, as pedagogically crucial, highlighting the idea of SimMan as both a form of equipment and 'as if' a real patient.

In the technical briefing, the tutor guided students as to the relevant features and functions of SimMan. The material composition of SimMan and the tutor's actions simulated a technical body defined by anatomy and function. However a clinical body was also simulated from the moment in the general briefing when details of the patient (name, gender, age, history) were shown on screen and discussed. Doings and sayings during the scenario are oriented towards a clinical body, and at the same time produce SimMan as such through forms of practical intelligibility: readings from the technical body were interpreted as clinically important, and clinical responses enacted, such as giving chest compressions. For brief moments in the scenario a technical body can re-emerge, as SimMan's limitations constrain practical intelligibility: he [sic; see Johnson, 2005] couldn't wiggle his toes when asked. A human body was simulated as the students provided therapeutic touch and asked about levels of pain and comfort, and through the vocalisation of the patient by the tutor or students. In the debriefing, the simulations of these three bodies folded together: comments referred to technical aspect, clinical aspects, and features of the performance that engaged the manikin as a person.

To be clear, these dimensions do not map directly onto Schatzki's (1996) being a body, having a body, and the instrumental body. Rather the link to Schatzki can be made through the key concepts of practical intelligibility and multiplicity. It is through the different ways in which students (inter)act with and make sense of SimMan that the technical, clinical, and human bodies are produced. These (inter)actions and forms of sense-making are themselves sites at which Schatzki's three notions of embodiment come into play (as discussed below). Students are, have, and use their bodies in performances that enact SimMan as a technical, clinical and human body.

Much of the learning activity in simulation stemmed from the fact that the simulated patient bodies were dynamic rather than static. This prefigured dynamism reflects material changes and evolving practical intelligibility that co-constitute a changing body. The scenarios we observed simulated a deteriorating patient so that clinical situations arose, demanding bodily actions in response. As opposed to the use of simulators for rehearsal of isolated techniques, the changing bodies in 
scenarios are crucial in supporting learning that moves away from isolated tasks to more complex clinical situations and their practices (Kelly et al., 2014).

\section{Performances: doings and sayings of a professional}

To support any kind of learning, we must do more than simulate patient bodies or other relevant features of professional settings. Even the use of real, live bodies (referred to as professional patients or standardised patients) requires sophisticated curricular and pedagogic devices (see Hopwood et al., 2014). Simulations of the kind we observed give students opportunities to perform as if they were already the professionals they are in the process of becoming. These performances comprise the doings and sayings of nursing, whereby these actions are performed amid, and attuned to relevant material features of a clinical setting. Materiality within dominant discourses places importance on what is called 'engineering fidelity' (Berragan, 2011). However notions of semantic and phenomenal fidelity (Dieckman et al., 2012) draw attention to scenarios and what people do and say. Thus performances around technologies just as pedagogically important as the realism of the simulator itself.

In the simulation itself, the students acting in clinical roles donned uniforms, referred to each other in professional roles, and executed actions of clinical assessment and care such as taking pulses, talking to the patient, and administering medications. The acting students get to embody professional practice in the three dimensions that Schatzki (1996) outlines. They get to be the body that performs every doing and saying, experience sensations (detecting a pulse) and feelings (anxiety when a patient goes into arrest). They have the body that becomes evident in moments of technical struggle or incompetence, and they use their instrumental bodies to accomplish higher order performances such as giving chest compressions.

Through their doings and sayings, the students inhabit their future selves as professionals. The social and material site, including practices of 'in-role' naming and a monitor indicating cardiac arrest, prefigures students' actions as nurses, and this same site reinforces them as such. In acting as nurses, the students render the materialities of the classroom (including the bodies of their acting peers) practically intelligible in clinical ways, and those material and social relations in turn constitute the actors as a team of professionals providing care for a patient. Here the simulated body (multiple) is only part of the many simulated performances that emerge. The material set-up, scenario design, briefing, and guidance by the tutor prefigures what happens, controlling some changes in the patient, setting up roles and shaping interactions (in our observations the tutor played either the role of the patient or a doctor, and could steer what unfolded). But this prefiguring does not sew up what happens: the totality of material arrangements, bodily performances, and forms of intelligibility is only partly fixed in advance. This raises questions about how far the logic of protocol-driven 'best-practice' can take us.

\section{Experiences: being a professional, and various kinds of other}

Ideas associated with experiential education (particularly Kolb, 1984) are widely referenced in existing literature (see Issenberg et al., 2011). We thus conclude our answer to the question 'what is being simulated?' by considering the kinds of experiences that emerged through the scenarios we observed. We draw on sociomaterial ideas to take this question into important new territory.

Fritz, Gray \& Flangan (2008) distinguish between a simulator, a device that attempts to recreate characteristics of the real world, and simulation, an educational technique that recreates all or part of a clinical experience. The term 'recreation' here indicates a foundational mirror logic that pervades literature on simulation. The metaphors vary: recreation, reproduction, reflection, fidelity - but the sense of a more or less accurate and complete version of something stable and external is common. Ideas of psychological fidelity- reproducing the cognitive and affective features or demands of a situation - and phenomenal fidelity (Dieckman et al., 2012) extend notions of 
material mirroring of reality into experiential dimensions. Within a non-representationalist, sociomaterial approach, experience and materiality are not taken as separate, but rather as mutually constituted through performances. This deflects the mirroring logic that underpins discourses of fidelity. Schatzki's (1996) notion of being a body refers to the body capable of experiencing sensations and feelings. What such experiences are made available to students in scenarios like those we observed? Bodily actions, interactions and talk during the simulation, supported by comments made in debriefings, suggested that the students acting in clinical roles had intense experiences of panic, uncertainty, and relief as the deteriorating patients they were caring for stabilised.

Such experiences need to be considered not only in relation to future bodily performances, but also in terms of the embodied history of students. It is often the case that students have varying levels of prior experience in professional settings: some nursing students may have already worked as enrolled nurses, while others come to a degree straight from school. What Schatzki (1996) calls the 'bodily repertoire' of gestures, actions and felt sensations varies among students, multiplying what the simulation constitutes in terms of embodied experience. This is further layered with variations in what students have participated in or observed on clinical placements.

The experiences for students acting as the (voice of the) patient and his [sic] relatives are very different. They do not experience temporary embodiment of their future professional selves at work, but rather take on the doings and sayings of other kinds of bodies they will encounter when they are at work. The pedagogical idea here is that the experience of playing a relative or patient (even if only through speaking the patient's voice) leaves an embodied trace, helping students empathise with others in the 'real' world - supporting learning objectives relating to producing professionals skilled in delivering patient-centred care (Dieckman \& Krage, 2013). The debriefing seeks to make these embodied experiences vicariously available to others through explanations of how it felt by acting students.

In the scenarios we observed, some students act as team leaders, and others as registered nurses: irrespective of prior professional service, these roles lie outside of students' direct embodied experience. These students are asked to carry out unscripted performances beyond the range of duties that will be expected of them in their first months of 'real' work. Here the simulation makes use of its breaks from reality to allow students to take on roles that can be anticipated further into the future. Herein lies significant pedagogic potential to foster a particular kind of learning. Rather than focusing on pre-specified performances, for which demonstrated competence is taken to indicate readiness for work, students are confronted with the experience of being asked to undertake new and challenging tasks for the first time. This is a common experience in professional settings, where university qualifications do not mark the end of work-related learning. The experience of stepping into such situations may support meta-learning in students: not learning to perform particular known tasks, but learning to perform and cope when encountering something for which one does not feel fully prepared. This meta-learning avoids the trap of trying to specify in advance all that needs to be learned to perform a practice (Hager, 2011), and instead equips students with skills in coping with the fact that to do so is impossible.

What of the students who observe their acting peers? The limited availability of more hi-tech (and costly) simulation equipment, such as SimMan, and other curricular pressures mean it is common for class sizes to exceed the number of available roles in any one simulation (Rochester et al., 2012). Even when multiple scenarios widen acting opportunities, this still leaves many (often the majority) of students observing their peers for much of the time. The pedagogies of embodying the performances (doings, sayings, making things practically intelligible) of a future professional self are not directly available to observers. However this opportunity may allow them to 'see' bodies like theirs perform tasks in more or less fluid and accomplished ways: watching peers struggle 
offers different learning opportunities from watching polished performances by experienced professionals. Our data suggested that some of the observing students experienced sensations of panic or concern when the patient goes into arrest (as was commented by some during debrief, and evident from their bodily gestures when watching the simulation). Looking back at the literature, we noted that guidance for debriefing tended to focus on the actors, folding in observers for particular kinds of commentary as non-participants (Issenberg et al., 2005). What seems lacking is a sense of acknowledging observation as an embodied experience in itself and further, its briefing and debriefing . This simple extension of key tenets of experiential learning could render observation a richer learning experience.

Some of the tutor's comments in the debriefings cued us to a second form of meta-learning through observation of simulation, pointing to additional ways in which the pedagogic potential of observation might be exploited. For instance, when the discussion identified less polished aspects of the acting students' performances, and when those actors described uncertainty in or unfamiliarity of the task, tutors encouraged students to make use of opportunities to learn by watching others in their 'real' work settings. These realities were not a distant spectre for these students, whose graduation lay only weeks away. Scaffolded and debriefed appropriately, observing students can embody their future professional selves as observers in work. In Schatzkian terms, simulation can create experiences that help students render the materialities of work, including the bodily performances of peers/colleagues, and the communicative acts that unfold practically intelligible as tools to help them learn.

Through the use of simulations, students might be supported to direct their attention and develop a nuanced professional gaze that renders their work environments more pedagogically rich. Sensitive observation forms part of the bodily repertoire of the future professional, combining the instrumental body with forms of understanding that render everyday objects and performances intelligible as sites of learning. This recasts notions of engineering fidelity (the realism of the simulated work setting) and the embodied performances of the actors: the pedagogic function makes the sites of practice available to observing others in pedagogically rich ways. The question here is not how realistic the particular set-up or scenario is, but how well the performance and experience of observation equips students with the meta-skills to learn by watching at work

\section{A Sociomaterial Account of Simulation Teaching and Learning}

Rather than building directly on the existing discourses of realism and frameworks that prescribe (and proscribe) features and practices in simulation pedagogy, we posed the question 'What is being simulated?'. Taking a sociomaterial, practice theoretical, approach, we offered new ways of understanding the process of simulation., emphasising emergence, fluidity and multiplicity. Taking clinical simulation as a reference point, and drawing on data relating to scenarios for undergraduate nurses, we showed how multiple and fluid patient bodies were being simulated. Of course patient bodies are not always what is being simulated, but the ideas of multiplicity and emergent dynamism apply irrespective of the particular form of the material simulator. However simple or complex, realistic or otherwise, the material substrate of a simulation has technical features and limitations. With appropriate forms of practical intelligibility, these can co-constitute multiple, changing sites in which layers of meaning emerge, connecting the simulation time and space to future professional performances and settings.

The requirements, framing, scaffolding and debriefing of simulation scenarios make available opportunities for students to be a professional in a social and material environment that requires and reaffirms them as such, to experience their professional bodies in conscious moments of breakdown (incompetence, struggle etc.), and to use their bodies in performances as future professional selves. While such performances may be prefigured in the way the scenario is set up, particular 
performances emerge as a scenario unfolds, depending on how students act and react through their bodily doings and sayings and the ways they render the material set up practically intelligible.

Taking up the widespread framing of simulation pedagogy in terms of experiential education, we showed how a sociomaterial perspective surfaces multiplicity of experiences, taking meaning and matter as co-constitutive dimensions of simulation learning. The foregrounding of materiality, bodies and emergence through performance enabled us to describe links between prior learning, workplace experience, the present simulation moment, and future learning and performance in new ways. Importantly, this opens up questions about how simulation might avoid the pitfalls of trying to anticipate the learning required to ensure a set array of accomplished future performances.

What does this mean in terms of conceiving simulation pedagogy? In asking 'What is being simulated?' we deliberately let go of the questions of realism and narrowly defined effectiveness that have shaped much simulation literature. From a sociomaterial perspective, the questions 'How realistic is this simulation?' and 'How realistic should it be to enable students to learn to do particular things?' turn out not to be very important at all. Our Schatzkian analysis instead foregrounds ways in which the bundles of practices and material arrangements produce multiple sites that are at once sites of work-like set-ups and performances, but also which make deliberate breaks from realities of professional practice for pedagogic purposes (to 'be' a patient or relative, to take on roles beyond what is sanctioned in real settings etc.). A sociomaterial account also questions the desire to produce protocols or recipes for 'best practice' in simulation insofar as they rely on singular, linear logics. This is not to say that some curricular and pedagogic approaches may not be more or less effective in achieving certain learning objectives, but it does shift the basis for thinking about what those objectives might be, and what forms of material set up and intelligibility are required to produce pedagogically rich performances and experiences for students.

This paper responds to repeated calls to enrich and extend the theoretical basis for research and pedagogic practice in simulation. However, our contribution also furthers the work of rethinking philosophical bases for understanding social phenomena change (see Fenwick et al., 2011; Mulcahy, 2013). Sociomaterial approaches are gaining prominence in educational theorising as the limitations of dominant metaphors of learning are recognised, and the need to develop embodied and material accounts of learning is taken up. A Schatzkian site ontology changes how we conceive materiality in learning, forming the basis for a highly embodied account anchored to metaphors of emergence and multiplicity. This offers a distinctive means to understand the role of higher education in professional education and formation that changes what it means to produce 'work-ready' graduates. We frame this in terms of embodied performances and experiences that are not limited by the narrowing logics of prescribed performance, but instead acknowledge the inevitability of unpreparedness that all professionals and professional educators must confront (Hager, 2011). A focus on practices does not excuse educational researchers from confronting challenging questions about whether, how, and to what extent higher education might anticipate this. While it would be foolish to pursue the promise of complete preparedness, a sociomaterial, specifically Schatzkian, approach offers a useful lens through which to understand how simulation can provide the basis for pedagogies that address the uncertainties of professional practice. This is based on principles of fluid emergence and performance rather than the static logic of the mirror.

\section{Acknowledgements}

The study reported here was funded by the Faculty of Arts and Social Sciences Research Development Grants Scheme 2013, within the University of Technology, Sydney. Approval was granted by the UTS Human Research Ethics Committee (\#201300292). The authors would like to thank the participating students, tutors and simulation technician, and the two reviewers whose comments were helpful in refining the manuscript. We would like to acknowledge the contribution 
of Kate Collier to the conception of the project, fieldwork, and early analytical discussions. We also wish to thank Madeleine Abrandt Dahlgren for her role as a critical friend, in particular her input into analysis, and her sharing of ideas relating to enactment of multiple bodies around the SimMan.

\section{References}

Arthur, C., Levett-Jones, T., \& Kable, A. (2013). Quality indicators for the design and implementation of simulation experiences: a Delphi study. Nurse Education Today, 33(11), 1357-1361. doi: 10.1016/j.nedt.2012.07.012

Berragan, L. (2011). Simulation: an effective pedagogical approach for nursing? Nurse Education Today, 31(7), 660-663. doi: 10.1016/j.nedt.2011.01.019

Crookall, D. (2011). Philosophy and simulation. Simulation \& Gaming, 42(2), 146-150. doi: $10.1177 / 1046878111406787$

Dieckmann, P. (2009). Simulation settings for learning in acute medical care. In P. Dieckmann (Ed.), Using simulations for education, training and research (pp. 40-138). Lengerich: Pabst.

Dieckmann, P., \& Krage, R. (2013). Simulation and psychology: creating, recognizing and using learning opportunities. Current Opinion in Anaesthesiology, 26(6), 714-720. doi: 10.1097/ACO.0000000000000018

Dieckmann, P., Molin Friis, S., Lippert, A., \& Østergaard, D. (2012). Goals, success factors, and barriers for simulation-based learning: a qualitative interview study in health care. Simulation \& Gaming, 43(5), 627-647. doi: 10.1177/1046878112439649

Fenwick, T., Edwards, R., \& Sawchuk, P. (2011). Emerging approaches to educational research: tracing the sociomaterial. London: Routledge.

Fritz, P. Z., Gray, T., \& Flanagan, B. (2008). Review of manequin-based high-fidelity simulation in emergency medicine. Emergency Medicine Australia, 20, 1-9. doi: 10.1111/j.17426723.2007.01022.x

Gonczi, A. (2013). Competency-Based Approaches: Linking theory and practice in professional education with particular reference to health education. Educational Philosophy and Theory, 45(12), 1290-1306. doi: 10.1080/00131857.2013.763590

Green, B. (Ed.). (2009). Understanding and researching professional practice. Rotterdam: Sense Publishers.

Hager, P. (2011). Theories of workplace learning. In M. Malloch, L. Cairns, K. Evans \& B. N. O'Connor (Eds.), The SAGE handbook of workplace learning (pp. 17-31). London: Sage.

Hager, P., Lee, A., \& Reich, A. (2012). Problematising practice, reconceptualising learning, imagining change. In P. Hager, A. Lee \& A. Reich (Eds.), Practice, learning and change: practice-theory perspectives on professional learning (pp. 1-14). Dordrecht: Springer.

Hopwood, N. (2014a). A sociomaterial account of partnership, signatures and accountability in practice. Professions \& Professionalism, 4(2). doi: 10.7577/pp.604

Hopwood, N. (2014b). Four essential dimensions of workplace learning. Journal of Workplace Learning, 26(6/7).

Hopwood, N. (2014c). The rhythms of pedagogy: An ethnographic study of parenting education practices. Studies in Continuing Education, 36(2), 115-131. doi: 10.1080/0158037X.2013.787983

Hopwood, N., Abrandt Dahlgren, M., \& Siwe, K. (2014). Developing professional responsibility in medicine: a sociomaterial curriculum. In T. Fenwick \& M. Nerland (Eds.), Reconceptualising professional learning: sociomaterial knowledges, practices, and responsibilities (pp. 171183). London: Routledge.

Issenberg, S. B., McGaghie, W. C., Petrusa, E. R., Lee Gordon, D., \& Scalese, R. J. (2005). Features and uses of high-fidelity medical simulations that lead to effective learning: a BEME systematic review. Medical Teacher, 27(1), 10-28. doi: 10.1080/01421590500046924

Johnson, E. (2005). The ghost of anatomies past: simulating the one-sex body in modern medical training. Feminist Theory, 6(2), 141-159. doi: 10.1177/1464700105053691

Johnson, E. (2008). Simulating medical patients and practices: bodies and the construction of valid 
medical simulators. Body \& Society, 14(3), 105-128. doi: 10.1177/1357034X08093574

Kaakinen, J., \& Arwood, E. (2009). Systematic review of nursing simulation literature for use of learning theory. International Journal of Nursing Education Scholarship, 6(1). doi: 10.2202/1548-923X.1688

Kelly, M. A., Forber, J., Conlon, L., Roche, M., \& Stasa, H. (2014). Empowering the registered nurses of tomorrow: students' perspectives of a simulation experience for recognising and managing a deteriorating patient. Nurse Education Today, 34(2), 724-729. doi: 10.1016/j.nedt.2013.08.014

Kemmis, S., Wilkinson, J., Edwards-Groves, C., Hardy, I., Bristol, L., \& Grootenboer, P. (2014). Changing education, changing practices. Dordrecht: Springer.

Kolb, D. (1984). Experiential learning: experience as the source of learning and development. New Jersey: Prentice Hall.

Manidis, M., \& Scheeres, H. (2013). Practising knowing: emergence(y) teleologies. Educational Philosophy \& Theory. doi: 10.1080/00131857.2013.763597

McGaghie, W. C., Issenberg, S. B., Petrusa, E. R., \& Scalese, R. J. (2010). A critical review of simulation-based medical education research: 2003-2009. Meducal Education, 44(1), 50-63. doi: 10.1111/j.1365-2923.2009.03547.x

Mol, A. (2002). The body multiple: ontology in medical practice. London: Duke University Press.

Mulcahy, D. (2013). Turning around the question of 'transfer' in education: tracing the sociomaterial. Educational Philosophy and Theory, 45(12), 1276-1289. doi: 10.1080/00131857.2013.763592

Nystrom, S., Dahlberg, J., Hult, H., \& Abrandt Dahlgren, M. (2014). Crossing locations of enacting and observing simulations: ways of constructing interprofessional learning. Second International ProPEL conference 'Professional Matters: Materialities and Virtualities of Professional Learning'. Stirling.

Reckwitz, A. (2002). Toward a theory of social practices: a development in culturalist theorizing. European Journal of Social Theory, 5(2), 243-263. doi: 10.1177/13684310222225432

Rochester, S., Kelly, M., Disler, R., White, H., Forber, J., \& Matiuk, S. (2012). Providing simulation experiences for large cohorts of 1 st year nursing students: evaluating quality and impact. Collegian, 19, 117-124. doi: 10.1016/j.colegn.2012.05.004

Schatzki, T. R. (1996). Social practices: a Wittgensteinian approach to human activity and the social. Cambridge: Cambridge University Press.

Schatzki, T. R. (2001). Introduction: practice theory. In T. R. Schatzki, K. Knorr Cetina \& E. von Savigny (Eds.), The practice turn in contemporary theory (pp. 1-14). London: Routledge.

Schatzki, T. R. (2002). The site of the social: a philosophical account of the constitution of social life and change. University Park, PA: Pennsylvania State University Press.

Schatzki, T. R. (2010a). Materiality and Social Life. Nature and Culture, 5(2), 123-149. doi: $10.3167 / \mathrm{nc} .2010 .050202$

Schatzki, T. R. (2010b). The timespace of human activity: on performance, society, and history as indeterminate teleological events. Lanham, MD: Lexington.

Schatzki, T. R. (2012). A primer on practices. In J. Higgs, R. Barnett, S. Billett, M. Hutchings \& F. Trede (Eds.), Practice-based education: perspectives and strategies (pp. 13-26). Rotterdam: Sense.

Schatzki, T. R., Knorr Cetina, K., \& von Savigny, E. (Eds.). (2001). The practice turn in contemporary theory. London: Routledge.

Schiavenato, M. (2009). Re-evaluating simulation in nursing education: beyond the human patient simulator. Journal of Nursing Education, 48(7), 388-394. doi: 10.3928/01484834-2009061506

Thrift, N. (2007). Non-representational theory: space, politics, affect. Abingdon: Routledge. 